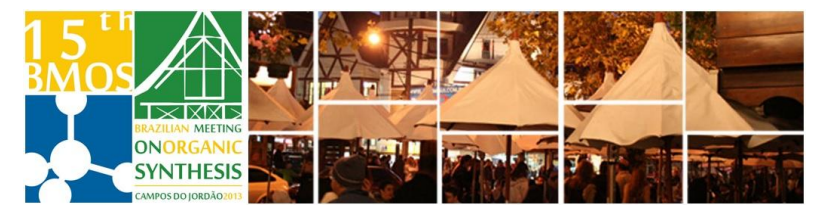

\title{
PEG: An Efficient Green Solvent for Organocatalytic Asymmetric Michael Addition
}

\author{
Karla S. Feu, * Sandrina I. R. M. Silva, Marco A. F. M. Junior, Alexander F. de la \\ Torre, Arlene G. Corrêa, Márcio W. Paixão
}

Federal University of São Carlos, São Carlos - São Paulo - Brazil

*karlafeu@gmail.com

Keywords: Michael addition, asymmetric organocatalysis, PEG.

\section{INTRODUCTION}

Green chemistry strongly influences chemical research, and there is still a big challenge respecting the requirement to use 'greener' reaction conditions. An important aspect of this field is the replacement of volatile organic solvent by non-flammable, nonvolatile, non-toxic and inexpensive "green solvents". In this regard, polyethylene glycol polymers (PEGs) have also been considered as a new class of green solvents. ${ }^{1}$

\section{RESULTS AND DISCUSSION}

We have recently developed a new class of catalyst and their applications on organocatalytic process in aqueous media. ${ }^{2}$ In the present work, we expanded our studies to evaluation in asymmetric Michael addition of aldehyde to $\beta$-nitrostyrene using PEG400 (Table 1).

Table 1. Studies and Optimization of the Reaction Parameters.

\begin{tabular}{|c|c|c|c|c|c|}
\hline \multirow[b]{2}{*}{ Entry } & \multirow{2}{*}{$\begin{array}{l}\|_{H}+ \\
\text { Solvent }\end{array}$} & \multicolumn{3}{|c|}{$\underset{10 \mathrm{~mol} \% \mathrm{PhCO}_{2} \mathrm{H}}{\mathrm{PEG}-400,4{ }^{\circ} \mathrm{C}}$} & \multirow[t]{2}{*}{$\frac{0^{\text {Ph }}}{\text { Time }}$} \\
\hline & & Yield $^{[a]}$ & $e e^{[b]}$ & $\mathbf{d r}^{[\mathrm{cc}]}$ & \\
\hline 1 & PEG-400 & $100 \%$ & $97 \%$ & $80: 20$ & $2 \mathrm{~h}$ \\
\hline 2 & PEG-400[d] & $92 \%$ & $95 \%$ & $76: 24$ & $1 \mathrm{~h}$ \\
\hline 3 & PEG-400[e] & $47 \%$ & $98 \%$ & $88: 12$ & $44 \mathrm{~h}$ \\
\hline 4 & PEG-400 $[\mathrm{ff}$ & $99 \%$ & $97 \%$ & $87: 13$ & $4 \mathrm{~h}$ \\
\hline
\end{tabular}

[a] solated yield. ${ }^{[b]}$ The ee values were determined by chiral HPLC. ${ }^{[c]}$ The d.r. values were determined by ${ }^{1} \mathrm{H}$ NMR spectroscopy and HPLC. [d] The reaction was performed at room temperature; ${ }^{[e]} 1$ mol $\%$ of catalyst $1 \mathrm{a}$. ${ }^{[\mathrm{f}} 5 \mathrm{~mol} \%$ of catalyst $1 \mathrm{a}$.

The best reaction condition is show in entry 4 of table 1 , by using $5 \mathrm{~mol} \%$ of catalyst 1 a having PEG400 as solvent in a $2 \mathrm{M}$ concentration. Others cocatalysts were also evaluated, however, benzoic acid delivered the desired product with superior results. Trying to improve the $d . r$ relationship, the structure of the organocatalyst was also evaluated.

Table 2. Organocatalyst Screening for the Michael Addition

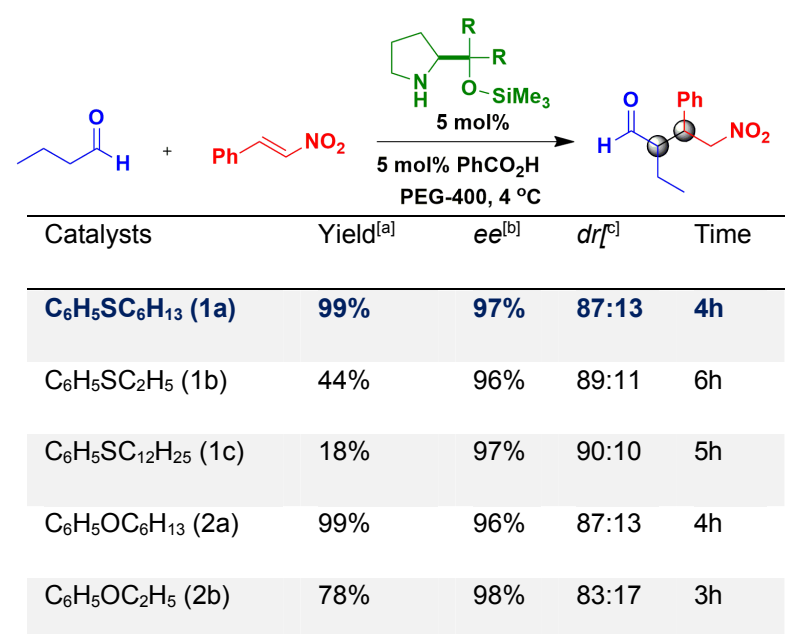

[a] ${ }^{[c]}$ The $d . r$. values were determined by ${ }^{1} \mathrm{H}$ NMR spectroscopy and HPLC.

From these results we could observed that catalyst $1 \mathrm{a}$ and benzoic acid as co-catalyst delivered the desired product in excellent levels of selectivity.

\section{CONCLUSION}

In summary we have demonstrated a highly stereoselective Michael addition of aldehydes to $\beta$ nitrostyrene using PEG-400 as green solvent. Additional studies on both solvent and catalyst reusability are ongoing.

ACKNOWLEDGEMENTS
${ }^{1}$ Capelo, C.; Fisher, U.; Hungerbuhler, K. Green Chem., 2007, 9,
927.
2 [a] Deobald, A. M.; Corrêa, A. G.; Rivera, D. G.; Paixão, M. W.
Org. Biomol. Chem. 2012, 10, 7681. [b] Feu, K. S.; Deobald, A.
M.; Narayanaperumal, S.; Corrêa, A. G.; Paixão, M. W. Eur. J.
Org. Chem. 2013, DOI: 10.1002/ejoc.201300431.

